\title{
MODULAÇÃO DA TEMPERATURA E DA VAZÃO DO AR NA SECAGEM DE GRÃOS DE SOJA EM LEITO FIXO
}

\author{
T. Z. CHEDLOVSKI ${ }^{1}$, H. D. S. SALINAS ${ }^{1}$, R. O. DEFENDI ${ }^{1}$, P. R. PARAÍSO e L. M. de M. \\ JORGE $^{1}$
}

${ }^{1}$ Universidade Estadual de Maringá, Departamento de Engenharia Química E-mail para contato:1mmj@deq.uem.br

\begin{abstract}
RESUMO - Um dos principais gastos inerentes à cadeia produtiva da soja é a secagem dos grãos colhidos na lavoura (15-18\% em base úmida) até a condição de armazenagem (11-12\% em base úmida). Uma alternativa para redução dos gastos energéticos neste processo está na aplicação da operação periódica que pode levar a um menor consumo energético. Neste contexto, efetuaram-se experimentos de secagem de soja em leito fixo tanto em operação convencional quanto em operação periódica com o mesmo consumo energético, visando avaliar se há redução do teor de umidade final na operação periódica em relação à secagem convencional, caracterizando assim uma melhora no desempenho do secador. Para isso, foi utilizado um secador de leito fixo em escala de bancada, ao qual foi imposta a modulação na temperatura e na vazão do ar de alimentação. Os resultados obtidos revelaram que a operação periódica mostrou ser mais eficiente, pois as taxas de secagem foram maiores, o que pode levar a uma redução no tempo e no consumo energético do processo.
\end{abstract}

\section{INTRODUÇÃO}

Uma etapa fundamental durante a produção dos grãos é o processo de secagem que auxilia garantir as condições ideais de armazenamento para se evitar perdas e manter a qualidade do produto estocado. Contudo, o custo do processo de secagem na produção desses grãos é significativo. Biagi et al. (2002) argumentam que este processo necessita de alta demanda de energia calorífica e mecânica para o aquecimento e movimentação do ar. De acordo com Silva et al. (2000), a secagem em temperaturas altas pode consumir $60 \%$ ou mais do total de energia usada na produção de produtos agrícolas.

Uma alternativa para redução dos custos do processo de secagem é a redução do gasto energético do processo que pode ser alcançada pelo uso da operação intermitente, a qual opera com as condições do ar como sua temperatura e vazão em regime transiente, ao contrário da operação tradicional que opera com o ar em condições fixas em regime permanente. A secagem com entradas transientes pode beneficiar o processo de secagem potencializando os transportes de massa e de energia envolvidos no processo. Segundo Chua et al. (2003), a secagem intermitente é benéfica para produtos cuja secagem é controlada pelos transportes difusivos internos no material, que é o caso da soja.

É interessante optar por variar a energia fornecida ao sistema para este tipo de material cujos efeitos difusivos controlam a secagem, pois pode ocorrer de se fornecer uma quantidade 
desnecessária de energia, uma vez que a migração de água até a superfície é o efeito que controla o processo. Assim, em secagem intermitente pode-se fornecer energia para evaporar a água ao passo que em intervalos estabelecidos pode-se reduzir ou até mesmo cessar esse fornecimento de energia durante o tempo necessário para que esta difusão de água até o gás ocorra.

Recentemente, a secagem intermitente de alguns produtos agrícolas tem sido estudada por um número significativo de pesquisadores (Chua et al., 2003; Holowaty et al., 2012; Kowalski e Pawlowski, 2011; Meneghetti et al., 2012; Oliveira \& Rocha, 2007; Putranto et al., 2011). Um dos principais objetivos da secagem intermitente é minimizar os gastos energéticos e alcançar e manter as melhores qualidades dos produtos (Putranto et al., 2011). A secagem especialmente em altas temperaturas pode danificar os materiais. Alguns estudos apontaram que a operação intermitente pode reduzir o tempo efetivo de secagem e pode melhorar a qualidade do material seco (Chong e Law, 2011; Farkas et al., 1997; Ong et al., 2012; Kowalski e Szadzinska, 2014) em comparação com os resultados obtidos na operação convencional.

Neste contexto, objetivou-se efetuar experimentos de secagem de soja em leito fixo tanto em operação convencional quanto em operação periódica em condições onde ambas as operações demandem o mesmo consumo energético e a mesma demanda de ar e tempo de secagem, visando avaliar se há melhora no desempenho do secador, caracterizado pelo aumento da quantidade de água evaporado no final do processo.

\section{METODOLOGIA}

Para realização dos experimentos, utilizou-se um secador cilíndrico de leito fixo com 6 $\mathrm{cm}$ de diâmetro interno e $30 \mathrm{~cm}$ de comprimento. O secador foi isolado com lã e o material utilizado nos testes foi grãos de soja do tipo EMBRAPA 48, os quais foram fornecidos pela cooperativa COCAMAR. O ar do sistema é fornecido por um compressor em cuja linha de tubulação há um rotâmetro para quantificar a vazão de ar. O ar segue para um aquecedor elétrico que possui um dispositivo para regular a voltagem aplicada. Em seguida, o ar percorre o leito do secador, onde há vários termopares situados em diferentes posições desde a entrada até a saída do secador.

Primeiramente, ajustou-se a vazão do ar e sua temperatura inicial ligando a resistência aguardando-se até que o ar atinja temperatura constante. A temperatura, a umidade absoluta e a umidade realtiva foram medidas tanto para o ar de secagem quanto para o ar ambiente. Os trinta centímetros do leito do secador isolado foram preenchidos com soja, cuja massa foi quantificada. Quatro amostras da soja utilizada foram levadas em estufa a $105{ }^{\circ} \mathrm{C} \pm 2{ }^{\circ} \mathrm{C}$ durante 24 horas a fim de se determinar o teor de umidade inicial.

Com o leito preenchido, a linha do ar de secagem foi plugada na entrada do secador e secou-se o material durante 1 hora. As temperaturas em cada termopar foram medidas ao longo do processo. O psicrômetro foi acoplado na saída do secador para medir a umidade absoluta e a temperatura do ar que deixa o leito. No final do processo, a massa de soja seca foi quantificada e quatro amostras foram levadas em estufa a $105^{\circ} \mathrm{C} \pm 2{ }^{\circ} \mathrm{C}$ durante 24 horas para se determinar o teor médio de umidade final da soja. 
Foram realizados dois tipos diferentes de experimentos, sendo um com modulação apenas da temperatura do ar na entrada do secador mantendo sua vazão constante e outro com a modulação apenas da vazão do ar mantendo a temperatura constante (aquecedor desligado). No primeiro caso, foram feitas perturbações alternadas entre dois valores fixos na porcentagem da voltagem imposta à resistência do secador em intervalos constantes ao passo que a vazão do ar foi fixada no valor constante de $100 \mathrm{~L} / \mathrm{min}$. Dessa forma, a temperatura na entrada do secador variou periodicamente conforme o ar era aquecido e resfriado. No segundo caso, a secagem foi realizada com o ar em temperatura constante e ambiente, sendo que o aquecedor elétrico permaneceu desligado durante todo o processo. Foram impostas modulações na vazão do ar entre dois valores fixos em intervalos constantes. Os valores das perturbações da porcentagem da voltagem e da vazão do ar e os valores dos intervalos entre cada perturbação estão apresentados na Tabela 1.

Para cada secagem periódica, uma secagem convencional (temperatura e vazão de entrada do ar constantes durante todo o processo) foi conduzida no mesmo dia para evitar interferências inerentes às condições climáticas nas análises comparativas entre os rendimentos de ambas as operações. As operações convencionais foram realizadas de forma a consumir o mesmo gasto energético referente ao aquecimento do ar, a mesma demanda de ar (trabalhou-se com a vazão média da operação periódica) e o mesmo tempo de secagem em relação às quantidades obtidas de suas respectivas secagens periódicas. A quantidade de energia consumida durante a operação periódica foi calculada por meio da Equação 1.

$$
E_{P}=\dot{m}_{a r} \int c p_{a r} \cdot T a_{P} \cdot d t
$$

Em que $T a_{P}$ é a temperatura do ar de alimentação da operação periódica. Como a temperatura do ar é constante em operação convencional, a energia consumida no aquecimento do ar para a operação convencional é calculada conforme a Equação 2.

$$
E_{C}=\dot{m}_{a r} c p_{a r} \cdot T a_{C} \cdot t
$$

Em que $T a_{C}$ é a temperatura do ar de alimentação da operação convencional. Para garantir o mesmo consumo energético em ambas as operações, a temperatura do ar na entrada do secador para a operação convencional foi determinada calculando uma média para a temperatura na entrada do secador de sua respectiva operação periódica. Assim, a energia necessária para aquecer o ar foi a mesma em ambas as operações conduzidas no mesmo dia. Essa temperatura média foi calculada integrando numericamente a Equação 3.

$$
T a_{C}=\frac{\int T a_{P} \cdot d t}{\int d t}
$$

\section{RESULTADOS}

Observou-se que a operação periódica pode levar a maiores rendimentos uma vez que as taxas de secagem foram maiores em comparação com os resultados obtidos em operação convencional. Foi constatado que a porcentagem de água evaporada foi maior para todos os experimentos em operação periódica em comparação com suas respectivas operações 
convencionais. A Tabela 1 apresenta a porcentagem de água evaporada para cada par de experimento de operação periódica com sua respectiva operação convencional. A Equação 4 foi utilizada para calcular a porcentagem de água evaporada no final do processo.

$$
M_{e v}=\frac{m_{e v}}{y_{0} \cdot m_{s}} \cdot 100 \%
$$

Em que $M_{e v}$ é a porcentagem da massa de água evaporada, $m_{e v}$ é a massa de água evaporada, $y_{0}$ é a umidade da soja inicial em base úmida e $m_{s}$ é a massa de soja inicial presente no leito.

Tabela 1 - Porcentagem de Água Evaporada (\%) e Perturbações na Alimentação do Ar.

\begin{tabular}{cccccc}
\hline \multicolumn{3}{c}{ Modulação da Temperatura } & \multicolumn{3}{c}{ Modulação da Vazão } \\
\hline $\begin{array}{c}\text { Voltagem (\%) / } \\
\text { Intervalo (min) }\end{array}$ & Periódica & Convencional & $\begin{array}{c}\text { Vazão (L/min) / } \\
\text { Intervalo (min) }\end{array}$ & Periódica & Convencional \\
\hline $0-20 / 10$ & 33,1 & 27,6 & $200-40 / 10$ & 27,9 & 23,2 \\
$0-20 / 10$ & 28,6 & 22,3 & $200-40 / 10$ & 26,0 & 22,9 \\
$20-0 / 10$ & 33,4 & 28,6 & $40-200 / 10$ & 26,6 & 23,3 \\
$20-0 / 10$ & 30,0 & 25,0 & $40-200 / 10$ & 24,0 & 21,5 \\
$0-20 / 30$ & 34,1 & 26,3 & $200-40 / 30$ & 28,8 & 24,3 \\
$0-20 / 30$ & 29,8 & 23,4 & $200-40 / 30$ & 24,7 & 22,3 \\
$0-20 / 5$ & 30,4 & 26,2 & $200-40 / 5$ & 28,5 & 24,4 \\
$0-20 / 5$ & 32,3 & 24,9 & $200-40 / 5$ & 23,3 & 20,3 \\
$0-27 / 10$ & 35,6 & 28,6 & $170-70 / 10$ & 29,9 & 23,6 \\
$0-27 / 10$ & 33,2 & 27,6 & $170-70 / 10$ & 25,3 & 21,2 \\
$0-15 / 10$ & 29,0 & 24,9 & $140-100 / 10$ & 26,4 & 21,6 \\
$0-15 / 10$ & 32,2 & 25,0 & $140-100 / 10$ & 22,5 & 19,1 \\
\hline
\end{tabular}

Um tratamento estatístico foi usado para analisar se há diferença significativa entre as médias das porcentagens de água evaporada das operações periódicas e convencionais. $\mathrm{O}$ método utilizado foi o teste t pareado descrito por Montgomery e Runger (2003). Este método é ideal para amostras de pequenos tamanhos com variâncias desconhecidas e para observação de duas populações de interesse quando os dados coletados são feitos em pares e em condições homogêneas.

Utilizou-se a função t.test do Software $\mathrm{R}$ com os dados das diferenças entre as porcentagens da operação periódica e convencional. $\mathrm{O}$ teste apontou que há diferença significativa entre estas porcentagens com $5 \%$ de significância. $O$ valor $p$ obtido foi de $4,751.10^{-09}$ para os experimentos com modulação de temperatura e de $1,303.10^{-07}$ para os experimentos com modulação da vazão. Assim, o tratamento estatístico confirmou a melhora 
no rendimento do secador com o uso da operação periódica com modulação das propriedades do ar na entrada do secador, uma vez que a quantidade de água evaporada foi significativamente maior em comparação com a quantidade evaporada em operação convencional, em casos em que ambas as operações foram realizadas com o mesmo gasto energético, mesmo tempo de secagem, mesma amostra de soja e mesma demanda de ar.

O perfil de umidade do ar na saída do secador também indicou uma melhora no rendimento do secador em operação periódica. Os níveis de umidade foram maiores em comparação com os níveis em operação convencional. Estes resultados evidenciam que a quantidade de água transferida para a fase gasosa foi maior em operação periódica. Observouse uma melhora nos transportes de massa e de energia envolvidos no processo, uma vez que as taxas de secagem foram maiores. Como as taxas de secagem não são linearmente dependentes da temperatura do ar, a operação periódica pode atingir um maior rendimento em comparação a operação com a temperatura do ar constante. A Figura 1 mostra o perfil de umidade do ar na saída do secador para os experimentos de modulação da temperatura com amplitudes de modulação da porcentagem da voltagem aplicada nas resistências de 15, 20 e $27 \%$.

Figura 1 - Umidade do Ar na saída do Secador para diferentes modulações da voltagem

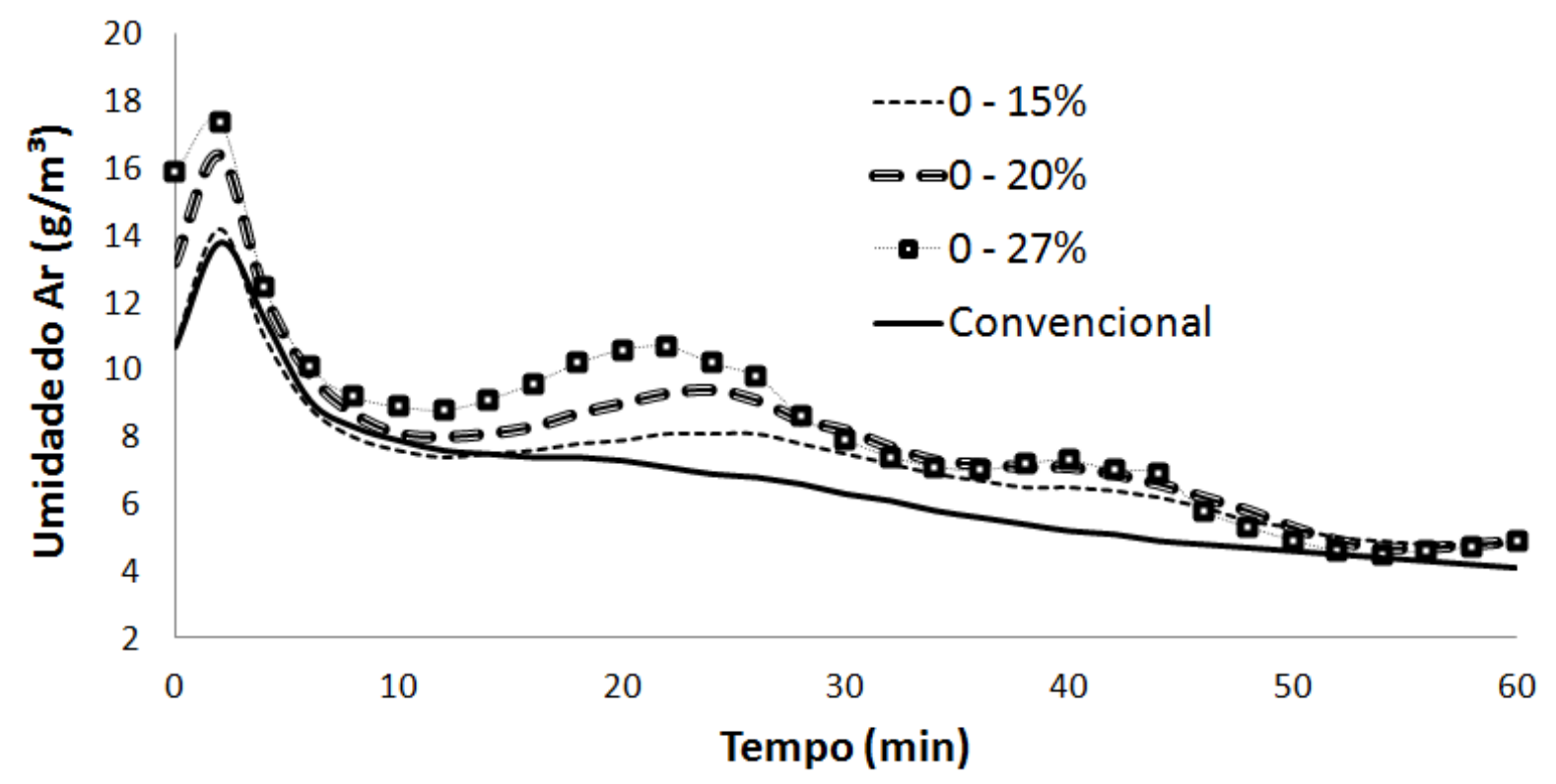

\section{CONCLUSÃO}

Observou-se dos resultados obtidos que a operação periódica pode aumentar o rendimento do secador em comparação à secagem convencional em casos em que ambas as operações tiveram o mesmo gasto energético, tempo de secagem e demanda de ar. A modulação da temperatura e vazão do ar na entrada do secador potencializou os transportes de massa e de energia envolvidos no processo, levando assim a maiores taxas de secagem. Testes estatísticos indicaram com $5 \%$ de significância que a porcentagem de água evaporada em 
operação periódica foi maior em comparação aos resultados obtidos em operação convencional. Uma vez que as taxas de secagem foram maiores, estes resultados indicam que para se atingir um determinado valor de umidade da soja pode ocorrer uma redução no tempo e no consumo energético do processo ao se aplicar a secagem periódica.

\section{REFERÊNCIAS}

BIAGI, J. D.; BERTOL, R.; CARNEIRO, M, C. Secagem de grãos para unidades centrais de armazenamento. In: LORINI, I; MIIKE, L. H.; SCUSSEL, V. M. Armazenagem de Grãos. Campinas, SP: IBG. 2002.

CHONG, C. H.; LAW, C. L. Application of Intermittent Drying of Cyclic Temperature and Step-Up Temperature in Enhancing Textural Attributes of Dehydrated Manilkara zapota. Drying Technology: An International Journal, v. 29 (2), p. 245-252, 2011.

CHUA, K. J.; MUJUMDAR, A. S.; CHOU, S. K. Intermittent drying of bioproducts - an overview. Bioresource Technology, v. 90, p. 285-295, 2003.

FARKAS, I.; RENDIK, Z. Intermittent thin layer corn drying. Drying Technology: An International Journal, v. 15 (6-8), p. 1951-1960, 1997.

HOLOWATY, S. A.; RAMALLO, L. A.; SCHMALKO, M. E. Intermittent drying simulation in deep bed dryer of yerba maté. Journal of Food Engineering, v. 111, p. 110-114, 2012.

KOWALSKI, S. J.; PAWLOWSKI, A. Intermittent drying of initially saturated porous materials. Chemical Engineering Science, v. 66, p. 1893-1905, 2011.

KOWALSKI, S.J.; SZADZINSKA, J. Convective-intermittent drying of cherries preceded by ultrasonic assisted osmotic dehydration. Chemical Engineering and Processing: Process Intensification, v. 82, p. 65-70, 2014.

MENEGHETTI, V. L.; AOSANI, E.; ROCHA, J. C. da; OLIVEIRA, M. de; ELIAS, M. C.; POHNDORF, R. S. Mathematical models for intermittent drying of rice. Revista Brasileira de Engenharia Agrícola e Ambiental, v. 16 (10), p. 1115-1120, 2012.

OLIVEIRA, C. A.; ROCHA, S. C. S. Intermittent Drying of Beans in a Spouted Bed. Brazilian Journal of Chemical Engineering, v. 24 (4), p. 571-585, 2007.

ONG, S. P.; LAW, C. L.; HII, C. L. Optimization of Heat Pump-Assisted Intermittent Drying. Drying Technology, v. 30, p. 1676-1687, 2012.

PUTRANTO, A.; XIAO, Z.; CHEN, X. D.; WEBLEY, P. A. Intermittent drying of mango tissues: implementation of the reaction engineering approach. Industrial \& Engineering Chemistry Research, v. 50, p. 1089-1098, 2011.

SILVA, J. S.; AFONSO, A. D. L.; DONZELLES, S. M. L. Secagem e Secadores. In: SILVA, J. S. Secagem e Armazenagem de Produtos Agrícolas. Viçosa: Aprenda Fácil, 2000. 